\title{
Concentração dos sais e da sacarose do meio MS na multiplicação in vitro e na aclimatização de batata
}

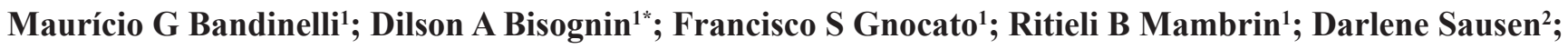 \\ Fernando T Nicoloso ${ }^{2}$ \\ ${ }^{1}$ UFSM, Depto. Fitotecnia, prédio 77, km 7, 97105-900 Santa Maria-RS; mgbandinelli@gmail.com; dilson.bisognin@ufsm.br (*autor \\ para correspondência); francisco.saccolgnocato@gmail.com; ritimambrin@yahoo.com.br; ${ }^{2} \mathrm{UFSM}$, Depto. Biologia, prédio 16; darlene_ \\ sn@yahoo.com.br; ftnicoloso@yahoo.com.br
}

\section{RESUMO}

Apesar da grande disponibilidade de informações sobre as etapas in vitro da micropropagação de batata, ainda não se conhece os seus efeitos sobre o comportamento das plantas durante a aclimatização. Desse modo, este trabalho teve como objetivo verificar a influência da concentração dos sais e da sacarose do meio MS, tanto na multiplicação in vitro quanto na aclimatização das mudas de batata em sistema de cultivo sem solo. $\mathrm{O}$ experimento foi conduzido em laboratório e telado, em um fatorial no delineamento inteiramente ao acaso, com quatro repetições de 20 explantes. Em laboratório foi avaliado o crescimento das plantas de três clones (Asterix, Macaca e SMINIA793101-3) de batata em função da combinação de concentrações dos sais ( $1 \frac{1}{2}$ MS e $\left.1 \mathrm{MS}\right)$ e de sacarose (30, 45 e $\left.60 \mathrm{~g} \mathrm{~L}^{-1}\right)$ do meio MS. Em telado foi avaliada a aclimatização das mudas destes tratamentos em dois sistemas (placa flutuante e substrato mineral) de cultivo sem solo. Durante o cultivo in vitro, exceto para o número de raízes, os clones avaliados mostraram resposta morfogênica variável. A elevação da concentração de sais do meio MS aumentou o número de folhas de 4,4 para 4,7 e diminuiu o número de raízes de 3,7 para 3,4. O incremento da concentração de sacarose do meio MS reduziu o número de folhas de 5,0 para 4,1 e o comprimento da parte aérea de 2,4 para 2,1 cm. Apenas as concentrações de sais do meio MS influenciaram a sobrevivência ex vitro das mudas de batata, sendo que a redução da concentração promoveu o aumento da sobrevivência, passando de $94,8 \%$ para $97,5 \%$. A aclimatização em sistema de cultivo sem solo não é limitante à produção de mudas de batata, podendo ser realizada tanto em placa flutuante quanto em substrato mineral, subirrigados com solução nutritiva.

Palavras-chave: Solanum tuberosum, sobrevivência ex vitro, produção de mudas, propagação vegetativa.

\section{ABSTRACT}

MS salt and sucrose concentrations in the in vitro multiplication and acclimatization of potato

Despite the good technological understanding about in vitro micropropagation of potato, there is no information regarding plantlet behavior during acclimatization. Thus, the aim of this work was to evaluate the effect of MS salt and sucrose concentrations in the in vitro multiplication and acclimatization of potato plantlets in soilless system. The experiment was carried out in laboratory and greenhouse as a factorial in a complete random design, with four replications of 20 explants. The in vitro multiplication of three potato clones (Asterix, Macaca, and SMINIA793101-3) was assessed in different salt (half and complete medium) and sucrose (30, 45 and $\left.60 \mathrm{~g} \mathrm{~L}^{-1}\right)$ concentrations of the MS medium. Plantlets of each treatment were acclimatized in two soilless systems (floating and mineral substrate) under greenhouse conditions. During in vitro multiplication, there were differences among clones, except for root number. Increasing the salt concentration of the MS medium increased the number of leaves from 4.4 to 4.7 , and reduced the number of roots from 3.7 to 3.4. Increasing the sucrose concentration of the MS medium reduced the number of leaves from 5.0 to 4.1 and the shoot length from 2.4 to $2.1 \mathrm{~cm}$. Only the MS salt concentrations affected the ex vitro survival of potato plantlets; reducing salt concentration increased the survival from $94.8 \%$ to $97.5 \%$. Acclimatization in soilless system is not a limiting step for the production of potato plantlets either in floating or mineral substrate, underirrigated with nutrient solution.

Keywords: Solanum tuberosum, ex vitro survival, plantlet production, vegetative propagation.

(Recebido para publicação em 16 de abril de 2012; aceito em 18 de abril de 2013) (Received on April 16, 2012; accepted on April 18, 2013)

\begin{abstract}
A micropropagação é uma técnica de grande impacto comercial, pois permite a produção massal de um genótipo de interesse, utilizando pequeno espaço físico e curto período de tempo (Grattapaglia \& Machado, 1998). Na cultura da batata (Solanum tuberosum) esta técnica vem sendo amplamente utilizada para produção de materiais livres de patógenos (fungos, bactérias e vírus), os quais são responsáveis pela
\end{abstract}

degenerescência da cultivar, reduzindo o seu potencial produtivo (Fortes \& Pereira, 2003).

A micropropagação de batata tem sido comumente realizada com a concentração plena dos sais do meio MS (Murashige \& Skoog, 1962), acrescido de 20 ou $30 \mathrm{~g} \mathrm{~L}^{-1}$ de sacarose, com ou sem a adição de ágar (Miyashita et al., 1996; Pereira \& Fortes, 2003; Pereira \& Fortes, 2004). Apesar desta observada adequação do meio de cultura ao crescimento in vitro da batata, são escassos os relatos na literatura sobre os seus efeitos na aclimatização das plantas. Em experimento realizado com mudas micropropagadas de diversas espécies, incluindo batata, foi constatado que a adição de 30 e $45 \mathrm{~g} \mathrm{~L}^{-1}$ de sacarose aumentou a sobrevivência das plantas durante a aclimatização (Riquelme et al., 1991). Para a cultura do moran- 
gueiro (Fragaria x ananassa), além do aumento da sobrevivência ex vitro das plantas com uso de concentrações crescentes de sacarose, foi constatado que a presença desta substância no meio MS teve importância fundamental para o desenvolvimento e incremento da biomassa das raízes (Calvete et al., 2000, 2002). De acordo com Díaz-Pérez et al. (1995), raízes formadas durante o cultivo in vitro podem ser importantes durante a aclimatização de mudas micropropagadas, pois interferem no suprimento de água para as plantas. Avaliando o cultivo in vitro de batata com $0 \mathrm{~g} \mathrm{~L}^{-1}$ e $30 \mathrm{~g} \mathrm{~L}^{-1}$ de sacarose, Badr et al. (2011) observaram maior produção de biomassa de raízes, menor número de folhas e comprimento de parte aérea com a adição de $30 \mathrm{~g} \mathrm{~L}^{-1}$ dessa fonte de carbono. Os autores verificaram ainda que o uso de $30 \mathrm{~g} \mathrm{~L}^{-1}$ de sacarose promoveu maior acúmulo de diversas substâncias, entre elas sacarose, glicose e frutose, as quais podem desempenhar papel importante durante a aclimatização ex vitro das plantas de batata.

Além da sacarose, a redução da concentração de sais do meio MS tem mostrado efeito sobre variáveis morfogênicas em plantas micropropagadas. Em videira (Vitis vinifera) foi verificado que a concentração de $50 \%$ dos sais do MS maximizou o número de raízes por planta (Biasi et al., 1998). Já para as cultivares $\mathrm{MC}$ e Adams de marmeleiro (Cydonia oblonga), o uso de $75 \%$ da concentração dos sais do MS proporcionou aumento na porcentagem de enraizamento, número e comprimento médios das raízes (Erig et al., 2004). Para cultivares de morangueiro, Pereira et al. (1999) constataram que a redução da concentração dos sais de MS favoreceu tanto o enraizamento quanto a formação de raízes pelas plantas. Portanto, para a cultura da batata, a avaliação e o ajuste da concentração dos sais e da sacarose do meio MS são necessários, devido à possibilidade de aumento da sobrevivência das plantas durante a aclimatização e, também, da redução dos custos de produção in vitro de mudas. Além disso, o advento da produção de minitubérculos de batata-semente em sistema de cultivo sem solo (Medeiros et al., 2002; Factor et al., 2007) requer a avaliação do comportamento das plantas durante a aclimatização neste sistema.

O objetivo deste trabalho foi verificar a influência da concentração dos sais e da sacarose do meio MS, tanto na multiplicação in vitro quanto na aclimatização das mudas de batata em sistema de cultivo sem solo.

\section{MATERIAL E MÉTODOS}

Os experimentos foram conduzidos em laboratório e telado da Universidade Federal de Santa Maria, Santa Maria-RS, durante o cultivo de primavera de 2007. No cultivo in vitro foram avaliados três clones de batata (Asterix, Macaca e SMINIA793101-3), duas concentrações dos sais ( $1 / 2 \mathrm{MS}$ e $1 \mathrm{MS})$ e três de sacarose (30, 45 e $\left.60 \mathrm{~g} \mathrm{~L}^{-1}\right)$ do meio MS. Os meios de cultura, com as diferentes concentrações de sais e de sacarose, tiveram o $\mathrm{pH}$ ajustado para 5,70 $\pm 0,02$ e o ágar adicionado na proporção de $6,75 \mathrm{~g} \mathrm{~L}^{-1} \mathrm{e}$, logo após, autoclavados por 15 min a $121^{\circ} \mathrm{C}$ e pressão de $1 \mathrm{~atm}$. Os explantes, segmentos nodais com $0,5 \mathrm{~cm}$ de comprimento, contendo uma gema e uma folha, foram inoculados ao meio de cultura e mantidos em sala de crescimento com temperatura de $25 \pm 2^{\circ} \mathrm{C}$ e fotoperíodo de 16 horas de luz e 8 horas de escuro, com intensidade luminosa média de $20 \mu \mathrm{mol} \mathrm{m}^{-2} \mathrm{~s}^{-1}$, fornecida por lâmpadas fluorescentes brancas frias.

Os tratamentos foram distribuídos em um fatorial $(3 \times 2 \times 3)$ no delineamento experimental inteiramente ao acaso, com quatro repetições. A unidade experimental foi um frasco de vidro de $150 \mathrm{~mL}$, contendo $20 \mathrm{~mL}$ de meio de cultura e 20 segmentos nodais, obtidos de plantas de batata previamente estabelecidas in vitro.

Após 15 dias de cultivo, as mudas foram retiradas do meio de cultura e as raízes lavadas com água corrente, para retirar todo o meio de cultura aderido ao sistema radicular. Foram avaliados, por planta, o número de folhas, o número de raízes e o comprimento da parte aérea $(\mathrm{cm})$ medida desde a inserção do explante, no meio de cultura, até o ápice da muda.

A aclimatização das plantas foi avaliada em condições de cultivo em telado, coberto com um filme de polietileno de 150 micras e as laterais protegidas com tela (antiafídeos). Foram empregados sistemas de aclimatização do tipo placa flutuante em solução nutritiva e com uso de substrato mineral (areia grossa), adaptados de Bisognin (2007). O sistema de placa flutuante em solução nutritiva (Figura 1A) foi instalado em uma bandeja de polietileno, com lâmina de 5 a $7 \mathrm{~cm}$ de solução nutritiva completa de condutividade elétrica (CE) de $1 \mathrm{dS} \mathrm{m}^{-1}$ descrita em Müller et al. (2007). Sobre a lâmina de solução nutritiva foi colocada uma placa de poliestireno expandido de $1,5 \mathrm{~cm}$ de espessura, com orifícios circulares de $3 \mathrm{~cm}$ de diâmetro. Em cada orifício foram colocadas 20 plantas, previamente fixadas em uma espuma de poliuretano de $3 \mathrm{~cm}$ de largura e 20 cm de comprimento. O sistema com uso de substrato (Figura 1B) foi composto por uma bandeja de polietileno, na qual foi colocada uma camada de aproximadamente $7 \mathrm{~cm}$ de brita média, com a função de drenar a solução. A camada de brita foi coberta por uma tela fina de polietileno para separar o substrato, constituído de uma camada de $5 \mathrm{~cm}$ de areia grossa (partículas entre 1 e $3 \mathrm{~mm}$ de diâmetro). Nesse sistema as plantas foram distribuídas em orifícios espaçados em $2 \times 2 \mathrm{~cm}$, sendo colocada uma planta em cada, e as subirrigações foram realizadas a cada duas horas no decorrer do dia. Para isso foram utilizados um programador digital e uma bomba de baixa vazão, sendo a solução nutritiva bombeada de forma a encharcar completamente o substrato, para que houvesse a formação de uma lâmina superficial de solução a qual foi drenada por dois orifícios, um situado na base e outro na parte superior da bandeja. Em ambos os sistemas de aclimatização, as plantas foram mantidas sombreadas, sob tela de polietileno com $50 \%$ de permeabilidade aos raios solares, por 15 dias, quando foi avaliada a porcentagem de sobrevivência.

Os tratamentos aplicados na multiplicação in vitro, somados ao fator sistema de aclimatização resultaram em um experimento fatorial (três clones $\mathrm{x}$ duas concentrações dos sais do meio MS $\mathrm{x}$ três concentrações de sacarose no meio $\mathrm{x}$ dois sistemas de aclimatização), o qual 
foi conduzido no delineamento inteiramente ao acaso, com quatro repetições de 20 plantas.

Os dados foram submetidos à análise de variância (teste F) e as médias comparadas pelo teste de Duncan $(\alpha=0,05)$, com o auxílio do programa estatístico SOC-NTIA/EMBRAPA (EMBRAPA, 1997). Dados de contagem foram transformados segundo a equação $\sqrt{x+0,5}$ e de porcentagem segundo a equação arcsen $\sqrt{x / 100}$.

\section{RESULTADOS E DISCUSSÃO}

O número de folhas por planta variou em função dos fatores avaliados. O clone Macaca apresentou o maior número de folhas, enquanto que o clone Asterix o menor, o que indica genótipo-dependência no crescimento das plantas in vitro. Em relação ao meio de cultura, o uso da concentração completa de sais do MS favoreceu o maior número de folhas por planta (Tabela 1) e, consequentemente, maior número de entrenós devido à associação desta variável com o número de folhas. A maior concentração de nitrogênio $(\mathrm{N})$ pode ter contribuído para este comportamento, visto que o $\mathrm{N}$ apresenta relação direta com o crescimento da parte aérea das plantas (Yin et al., 2003).

A elevação da concentração de sacarose de $30 \mathrm{~g} \mathrm{~L}^{-1}$ para $60 \mathrm{~g} \mathrm{~L}^{-1}$ acarretou diminuição do número de folhas (Tabela 1) e, consequentemente, de entrenós das mudas de batata durante o cultivo in vitro. Mohamed \& Alsadon (2010), testando concentrações de sacarose e a ventilação dos frascos no cultivo in vitro de batata, observaram que em frascos não ventilados houve decréscimo do número de entrenós por planta com o incremento da sacarose de 10 para 20 ou $30 \mathrm{~g} \mathrm{~L}^{-1}$. Badr et al. (2011) também observaram redução no número médio de folhas por planta quando a concentração de sacarose do MS foi aumentada de $0 \mathrm{~g} \mathrm{~L}^{-1}$ para $30 \mathrm{~g} \mathrm{~L}^{-1}$. Esses resultados, juntamente com o observado no presente trabalho, revelam tendência de redução do número de folhas e entrenós nas plantas de batata, à medida que a concentração de sacarose do meio de cultura é aumentada, sendo importante para trabalhos que levam em consideração a

Tabela 1. Número de folhas e de raízes por planta, de três clones de batata, após 15 dias de cultivo in vitro em diferentes concentrações de sais e de sacarose do meio MS (leaves and root number per plantlet of three potato clones after 15 days of in vitro cultivation in MS medium with different concentrations of salts and sucrose). Santa Maria, UFSM, 2007.

\begin{tabular}{lcc}
\hline Tratamentos & Folhas $\left(\mathbf{n}^{\mathbf{0}}\right)$ & Raízes $\left(\mathbf{n}^{\mathbf{0}}\right)$ \\
\hline Clones & & \\
\hline Macaca & $6,2 \mathrm{a}^{1}$ & $3,5 \mathrm{a}$ \\
SMINIA793101-3 & $3,8 \mathrm{~b}$ & $3,5 \mathrm{a}$ \\
Asterix & $3,4 \mathrm{c}$ & $3,7 \mathrm{a}$ \\
\hline Concentração de sais & & \\
\hline 1 MS & $4,7 \mathrm{a}$ & $3,4 \mathrm{~b}$ \\
$1 / 2$ MS & $4,4 \mathrm{~b}$ & $3,7 \mathrm{a}$ \\
\hline Sacarose (g/L) & & \\
\hline 30 & $5,0 \mathrm{a}$ & $3,5 \mathrm{a}$ \\
45 & $4,4 \mathrm{~b}$ & $3,6 \mathrm{a}$ \\
60 & $4,1 \mathrm{c}$ & $3,6 \mathrm{a}$ \\
\hline CV $(\%)$ & 5,3 & 6,2 \\
\hline
\end{tabular}

${ }^{1}$ Médias não seguidas pela mesma letra na vertical diferem entre si pelo teste de Duncan a $5 \%$ de probabilidade (means not followed by the same letter in the columns differ by Duncan test at $5 \%$ of probability).

Tabela 2. Comprimento da parte aérea $(\mathrm{cm})$ das plantas, de três clones de batata, após 15 dias de cultivo em duas concentrações de sais do meio MS (plantlet shoot length $(\mathrm{cm})$ of three potato clones after 15 days of in vitro cultivation in two salt concentrations of MS medium). Santa Maria, UFSM, 2007.

\begin{tabular}{lccc}
\hline Concentração de sais & Macaca & SMINIA793101-3 & Asterix \\
\hline $1 / 2 \mathrm{MS}$ & $3,4 \mathrm{aA}^{1}$ & $1,4 \mathrm{bC}$ & $2,0 \mathrm{aB}$ \\
$1 \mathrm{MS}$ & $3,7 \mathrm{aA}$ & $1,6 \mathrm{aB}$ & $1,7 \mathrm{bB}$ \\
\hline $\mathrm{CV}(\%)$ & & 7,1 & \\
\hline
\end{tabular}

${ }^{1}$ Médias não seguidas pela mesma letra, minúscula na vertical e maiúscula na horizontal, diferem entre si pelo teste de Duncan a 5\% de probabilidade (means not followed by the same lowercase letter in the columns and uppercase letter in the lines differ by Duncan test at $5 \%$ of probability).

taxa de multiplicação in vitro.

A biomassa de plantas de batata não foi avaliada neste trabalho, entretanto, é possível que a redução no número de folhas e, consequentemente, de entrenós não tenha sido acompanhada pela redução da biomassa das plantas, à medida que a concentração de sacarose foi aumentada. Em morangueiro, por exemplo, maiores quantidades de biomassa foram obtidas em plantas micropropagadas em meio de cultura contendo $45 \mathrm{~g} \mathrm{~L}^{-1}$ de sacarose, quando comparadas àquelas micropropagadas com 15 e $30 \mathrm{~g} \mathrm{~L}^{-1}$ (Calvete et al., 2002). Estes autores observaram ainda aumento na massa seca da parte aérea das plantas à medida que concentração de sacarose foi sendo incrementada. Em estudo com
Tabela 3. Comprimento da parte aérea $(\mathrm{cm})$ de plantas de batata, após 15 dias de cultivo in vitro em diferentes concentrações de sacarose do meio MS (plantlet shoot length $(\mathrm{cm})$ of potato plants after 15 days of in vitro cultivation in MS medium with different concentrations of sucrose). Santa Maria, UFSM, 2007.

\begin{tabular}{lc}
\hline $\begin{array}{l}\text { Sacarose } \\
(\mathrm{g} / \mathrm{L})\end{array}$ & $\begin{array}{c}\text { Comprimento da } \\
\text { parte aérea }(\mathbf{c m})\end{array}$ \\
\hline 30 & $2,4 \mathrm{a}^{1}$ \\
45 & $2,3 \mathrm{a}$ \\
60 & $2,1 \mathrm{~b}$ \\
\hline $\mathrm{CV}(\%)$ & 7,1 \\
\hline
\end{tabular}

${ }^{1}$ Médias não seguidas pela mesma letra diferem entre si pelo teste de Duncan a 5\% de probabilidade (means not followed by the same letter differ by Duncan test at 5\% of probability). 
Tabela 4. Sobrevivência (\%) de plantas de batata micropropagadas in vitro sob diferentes concentrações de sais e de sacarose do meio MS, após 15 dias de aclimatização em dois sistemas de cultivo sem solo (survival (\%) of potato plantlets micropropagated in vitro at diferent MS salt and sucrose concentrations after 15 days of acclimatization in two soilless cultivation systems). Santa Maria, UFSM, 2007.

\begin{tabular}{lccc}
\hline Tratamentos & Macaca & SMINIA793101-3 & Asterix \\
\hline Placa flutuante & $91,9 \mathrm{bB}^{1}$ & $99,1 \mathrm{aA}$ & $98,7 \mathrm{aA}$ \\
Substrato & $95,4 \mathrm{aA}$ & $94,6 \mathrm{bA}$ & $97,2 \mathrm{aA}$ \\
\hline
\end{tabular}

\begin{tabular}{ll}
\hline Concentração de sais & \\
\hline $1 / 2 \mathrm{MS}$ & $97,5 \mathrm{a}$ \\
$1 \mathrm{MS}$ & $94,8 \mathrm{~b}$ \\
\hline
\end{tabular}

\begin{tabular}{lc}
\hline Sacarose $\left(\mathrm{g} \mathrm{L}^{-1}\right)$ & \\
\hline 30 & $94,8 \mathrm{a}$ \\
45 & $97,1 \mathrm{a}$ \\
60 & $96,5 \mathrm{a}$ \\
\hline $\mathrm{CV}(\%)$ & 9,7 \\
\hline
\end{tabular}

${ }^{1}$ Médias não seguidas pela mesma letra, minúscula na vertical e maiúscula na horizontal, diferem entre si pelo teste de Duncan a $5 \%$ de probabilidade (means not followed by the same lowercase letter in the columns and uppercase letter in the lines differ by Duncan test at $5 \%$ of probability).

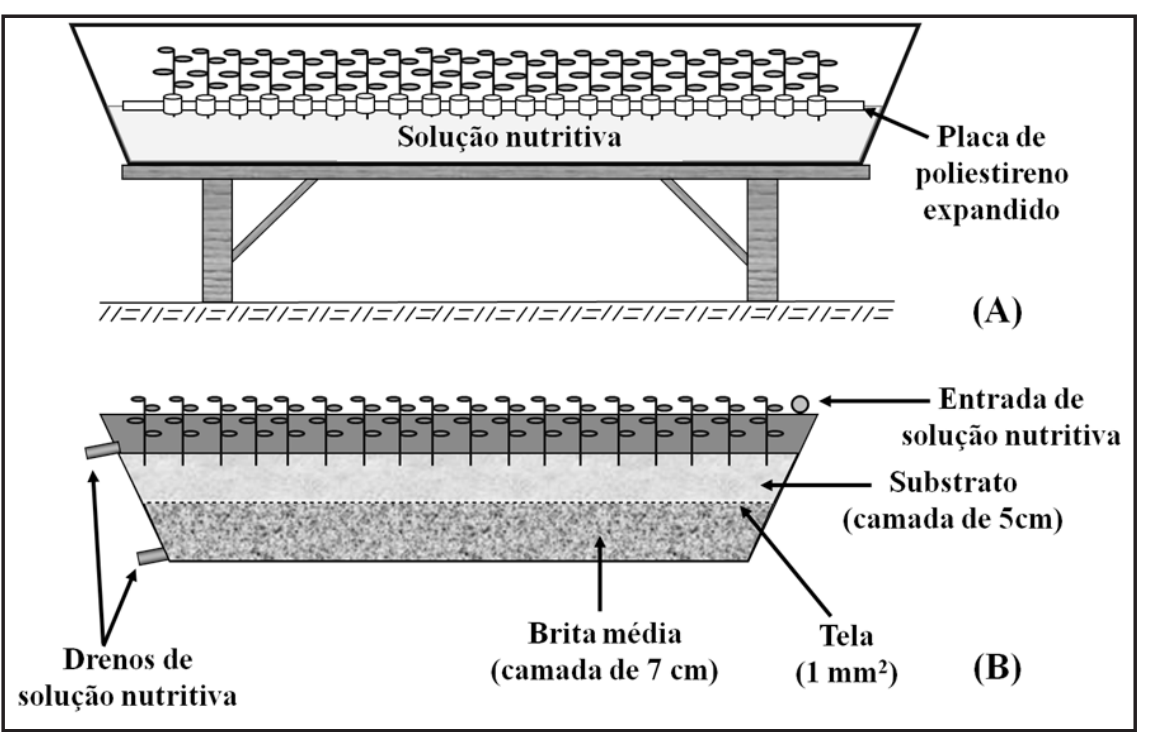

Figura 1. Ilustração dos sistemas de cultivo sem solo, do tipo placa flutuante em solução nutritiva (A) e com uso de substrato mineral (B), empregados na aclimatização das plantas de batata (illustration of soilless systems type floating plate in nutrient solution (A) and with the use of mineral substrate (B) used in the acclimatization of potato plantlets). Santa Maria, UFSM, 2007.

batata, ao elevar a concentração de sacarose de $0 \mathrm{~g} \mathrm{~L}^{-1}$ para $30 \mathrm{~g} \mathrm{~L}^{-1}$, Badr et al. (2011) observaram aumento apenas na biomassa das raízes. No entanto, houve elevação de diversas substâncias acumuladas nos tecidos das plantas, entre elas a sacarose, a glicose e a frutose. Alguns autores (Capellades et al., 1991; Premkumar et al., 2001) afirmam que reservas acumuladas durante o cultivo redução da concentração promoveu o aumento do número de raízes (Tabela 1). Esse resultado foi semelhante ao observado em trabalhos com plantas de crisântemo (Dendranthema grandiflora) cultivar Orange Reagen, plantas de Vitis vinifera, com as cultivares MC e Adams de marmeleiro (Cydonia oblonga) e com plantas de morangueiro, cultivares Hofla e Tangi por Oliveira et al. (1996), Biasi et al. (1998), Erig et al. (2004) e Pereira et al. (1999), respectivamente. Estes últimos autores, entretanto, observaram diferença quanto ao número de raízes entre as cultivares, o que não foi verificado neste trabalho com batata. Uma das explicações para o aumento do número de raízes com a redução da concentração dos sais pode estar associada à variação na quantidade de $\mathrm{N}$ do meio de cultura, pois o aumento da concentração deste nutriente favorece o crescimento da parte aérea em detrimento das raízes (Huimei et al., 2007). Em plantas de ginseng brasileiro (Pffafia glomerata), por exemplo, o maior número de raízes por planta e a maior porcentagem de plantas enraizadas foram obtidos com a concentração de $\mathrm{N}$ equivalente a $50 \%$ daquela do meio MS (Russowski \& Nicoloso, 2003). O maior número de raízes formadas durante o cultivo in vitro pode favorecer a aclimatização, devido à maior capacidade de absorção de água pela planta (Díaz-Pérez et al., 1995).

Nos três clones estudados a concentração dos sais do meio MS afetou distintamente o comprimento da parte aérea. O clone Macaca, o qual apresentou o maior comprimento da parte aérea, não foi afetado pela variação da concentração de sais. Já os clones SMINIA793101-3 e Asterix apresentaram, respectivamente, redução e aumento no comprimento da parte aérea pela diminuição da concentração dos sais (Tabela 2). Maior crescimento da parte aérea devido ao uso de concentrações diluídas do MS também foi observado em plantas de gloxínia (Sinningia speciosa) e rainha-do-abismo (Sinningia leucotricha) (Paiva et al., 1997; Unemoto et al., 2006). Neste trabalho, exceto para o clone Macaca, a concentração de sais do meio MS afetou diferentemente os clones de batata, con- 
cordando com Vance et al. (2003) que afirmam existir variações entre espécies e genótipos de uma espécie, mesmo quando submetidos a uma condição nutricional idêntica.

Para as diferentes concentrações de sacarose utilizadas no cultivo in vitro, observou-se que o comprimento da parte aérea foi influenciado apenas pelo uso de $60 \mathrm{~g} \mathrm{~L}^{-1}$ (Tabela 3), que promoveu redução do tamanho das plantas. As concentrações de 30 e $45 \mathrm{~g} \mathrm{~L}^{-1}$, entretanto, não diferiram entre si. Este resultado foi semelhante ao obtido por Ribeiro et al. (2008) com plantas de copo-de-leite (Zantedeschia aethiopica). É provável que o aumento do potencial osmótico do meio de cultura, ocasionado pela adição de sacarose, tenha interferido no crescimento das plantas. Em morangueiro, Calvete et al. (2002) observaram que a elevação da concentração de sacarose do meio MS acima de $45 \mathrm{~g} \mathrm{~L}^{-1}$ foi acompanhada por uma diminuição na produção de biomassa pelas plantas, porém com um aumento no teor de matéria seca.

Durante a etapa de aclimatização das plantas de batata em telado, as concentrações de sacarose e de sais do meio MS não interagiram com nenhum outro fator. Somente foi observada interação entre clones e sistemas de aclimatização (Tabela 4), no qual o clone Macaca apresentou a maior percentagem de sobrevivência quando as plantas foram aclimatizadas em substrato mineral, enquanto que o clone SMINIA793101-3 apresentou a maior sobrevivência no sistema de placa flutuante em solução nutritiva. Para o clone Asterix, entretanto, não houve diferença entre os dois sistemas utilizados. A redução da concentração de sais do meio MS favoreceu o aumento da sobrevivência ex vitro, provavelmente pelo aumento do número de raízes que propicia o suprimento de água para a planta durante a aclimatização (Díaz-Pérez et al., 1995). Este resultado mostra ainda que é possível reduzir a concentração de sais do meio MS e os custos da micropropagação, sem prejuízos para a sobrevivência ex vitro das plantas de batata.

A concentração de sacarose adicionada ao meio MS não afetou a sobrevivência ex vitro das plantas de batata (Tabela 4). Este resultado contrasta com o obtido por Riquelme et al. (1991) que observaram o favorecimento da sobrevivência das plantas de batata pelo uso de concentrações entre 30 e $45 \mathrm{~g} \mathrm{~L}^{-1}$ e, também, por Calvete et al. (2000), com morangueiro, onde o aumento da concentração de sacarose do meio foi acompanhado pelo aumento da sobrevivência ex vitro das plantas. No caso da batata, diferentes clones e condições ambientais empregadas na condução da aclimatização podem ter contribuído para a divergência de resultados.

Mesmo com os diferentes resultados observados para os fatores testados, as porcentagens de sobrevivência ex vitro das plantas de batata foram altas, todas acima de $91 \%$ (Tabela 4 ), indicando que a aclimatização em sistema de cultivo sem solo não é crítica para a produção de mudas. Assim, as plantas podem ser aclimatizadas tanto em substrato quanto em placa flutuante, cuja escolha deve considerar a melhor adequação ao sistema de cultivo que será empregado para a produção dos minitubérculos de batata.

Na etapa de aclimatização, a sobrevivência ex vitro das plantas de batata foi influenciada tanto pelos clones quanto pelos sistemas de aclimatização, demonstrando não haver comportamento uniforme, apesar do elevado índice de sobrevivência dos mesmos.

O sistema de placa flutuante é muito simples, porém parte das raízes é perdida quando se retira a planta da espuma de poliuretano, o que pode prejudicar o crescimento inicial das mudas quando transferidas para o local de cultivo definitivo. No caso do substrato mineral, a vantagem está no fato das plantas serem aclimatizadas em condições muito similares àquelas de produção de minitubérculos e, portanto, não passariam por uma nova aclimatização. O sistema fechado com uso de areia como substrato vem sendo utilizado com sucesso no Programa de Genética e Melhoramento da UFSM para a aclimatização das plantas e para o enraizamento de estacas de segmentos nodais e apicais de batata e, em maior escala, para a produção de minitubérculos de batata-semente.

Os resultados obtidos com este trabalho evidenciaram que a aclimatização em sistema de cultivo sem solo não é limitante à produção de mudas de batata, podendo ser realizada tanto em placa flutuante quanto em substrato mineral, subirrigados com solução nutritiva. No entanto, deve-se dar preferência ao uso do sistema com substrato, pois este favorece a produção de mudas melhor adaptadas ao local definitivo de cultivo, reduz os danos ao sistema radicular durante o transplante e alia baixo custo e praticidade de manejo. Verificou-se ainda que a redução da concentração de sais de meio MS promove o aumento da sobrevivência ex vitro das plantas de batata e que a concentração de sacarose não afeta a sobrevivência das plantas de batata dos clones estudados. Todos estes resultados constituem-se em informações relevantes que podem vir a contribuir para reduzir os custos na produção de plantas in vitro e, consequentemente, de minitubérculos de batata em sistemas de cultivo sem solo.

\section{AGRADECIMENTOS}

À CAPES, pela concessão de bolsa, e ao CNPq, pelo financiamento parcial do Programa de Genética e Melhoramento de Batata e pela concessão de bolsas.

\section{REFERÊNCIAS}

BADR A; ANGERS P; DESJARDINS Y. 2011. Metabolic profiling of photoautotrophic and photomixotrophic potato plantlets (Solanum tuberosum) provides new insights into acclimatization. Plant Cell, Tissue and Organ Culture 107: 13-24.

BIASI LA; PASSOS IRS; POMMER CV. 1998. Micropropagação do porta-enxerto de videira Jales. Pesquisa Agropecuária Brasileira 33: 1587-1594.

BISOGNIN, DA. 2007. Produção de plantas matrizes de morangueiro. In: SEMINÁRIO SOBRE O CULTIVO HIDRÔPONICO DE MORANGUEIRO. Anais... Santa Maria: UFSM. p. 9-17.

CALVETE EO; KÄMPF AN; BERGAMASCHI H; DAUDT, RHS. 2000. Avaliação do crescimento de plantas de morangueiro durante a aclimatização ex vitro. Horticultura Brasileira 18: 188-192.

CALVETE EO; KÄMPF AN; SUZIN M. 2002. Concentração de sacarose no enraizamento in vitro de morangueiro. Horticultura Brasileira 20: 186-191.

CAPELLADES M; LEMEUR R; DEBERGH P. 1991. Effects of sucrose on starch accumulation and rate of photosynthesis in Rosa cultured in vitro. Plant Cell, Tissue Organ Culture 25: 21-16. 
DIÁZ-PÉREZ JC; SHACKEL KA; SUTTER EG. 1995. Effects of in vitro formed roots and acclimatization on water status and gas exchange of tissue cultured apple shoots. Journal of the American Society for Horticultural Science 120: 435-440.

EMBRAPA. 1997. Ambiente de software NTIA, versão 4.2.2: manual do usuário - ferramental estatístico. Campinas: Centro Nacional de Pesquisa Tecnológica em Informática para a Agricultura. 258p.

ERIG AC; SCHUCH MW; CHAVES AC. 2004. Enraizamento in vitro e aclimatização de mudas de marmeleiro cvs. MC e Adams, utilizadas como porta-enxerto para a pereira. Scientia Agraria 5: 61-68.

FACTOR TL; ARAUJO JAC; KAWAKAMI FPC; IUNCK V. 2007. Produção de minitubérculos básicos de batata em três sistemas hidropônicos. Horticultura Brasileira 25: 82-87.

FORTES GRL; PEREIRA JES. 2003. Batatasemente pré-básica: Cultura de tecidos. In: PEREIRA AS; DANIELS J (eds). O cultivo da batata na região sul do Brasil. Brasília: Embrapa Informação Tecnológica. p. 421-433.

GRATTAPAGLIA D; MACHADO MA. 1998. Micropropagação. In: TORRES A; CALDAS LS; BUSO JA (org). Cultura de tecidos e transformação genética de plantas. Brasília: EMBRAPA-CNPH. p. 183-260.

HUIMEI W; YUANGANG Z; HONGMEI L. 2007. Efficient rooting and root development after transfer of regenerated plantlets of Camptotheca acuminate. Eurasian Journal of Forest Research 10: 179-184.

MEDEIROS CAB; ZIEMER AH; DANIELS J; PEREIRA AS. 2002. Produção de sementes pré-básicas de batata em sistemas hidropônicos. Horticultura Brasileira 20: 110-114.

MIYASHITA Y; KITAYA Y; KUBOTA C; KOZAI
T. 1996. Photoautotrophic growth of potato plantlets as affected by explant leaf area, fresh weight and stem length. Scientia Horticulturae 65: 199-202.

MOHAMED MAH; ALSADON AA. 2010. Influence of ventilation and sucrose on growth and leaf anatomy of micropropagated potato plantlets. Scientia Horticulturae 123: 295-300.

MURASHIGE T; SKOOG F. 1962. A revised medium for rapid growth and bioassays with tobacco tissue cultures. Physiologia Plantarum 15: 473-497.

MÜLLER DR; BISOGNIN DA; ANDRIOLO JL; DELLAI J; COPETTI F. 2007. Produção hidropônica de batata em diferentes concentrações de solução nutritiva e épocas de cultivo. Pesquisa Agropecuária Brasileira 42: 647-653.

OLIVEIRA PD; PASQUAL M; PAIVA R. 1996. Efeito de diferentes concentrações do meio MS, nitrogênio e sacarose na micropropagação de crisântemo 'Orange Reagen'. Bragantia 55: 9-18.

PAIVA PDO; MAYER MBD; CAMPOS RJC; RODRIGUES VA; PASQUAL M. 1997. Propagação in vitro de gloxínia. Revista Brasileira de Horticultura Ornamental 3: 29-41.

PEREIRA JES; BIANCHI VJ; DUTRA LF; FORTES GRL. 1999. Enraizamento in vitro do morangueiro (Fragaria x ananassa Duchesne) em diferentes concentrações do meio MS. Ciência Rural 29: 17-20.

PEREIRA JES; FORTES GRL. 2003. Protocolo para produção de material propagativo de batata em meio líquido. Pesquisa Agropecuária Brasileira 38: 1035-1043.

PEREIRA JES; FORTES GRL. 2004. Organogênese de ápices meristemáticos de batata em meios de isolamento e multiplicação in vitro. Horticultura Brasileira 22: 197-201. PREMKUMAR A; MERCADO JA; QUESADA MA. 2001. Effects of in vitro tissue culture conditions and acclimatization on the contents of Rubisco, leaf soluble proteins, photosynthetic pigments, and $\mathrm{C} / \mathrm{N}$ ratio. Journal of Plant Physiology 158: 835-840.

RIBEIRO MNO; PASQUAL M; SILVA AB; RODRIGUES VA. 2008. Diferentes concentrações de sais do meio MS e de sacarose na multiplicação in vitro de Zantedeschia aethiopica L. Spreng. (copo-de-leite). Revista Ciência Agronômica 39: 101-106.

RIQUELME C; GUIÑAZU ME; TIZIO R. 1991. Pre-acondicionamento y aclimataccion em condicciones de invernáculo de plântulas micropropagadas de frutilla, menta, papa y vid. Phyton 52: 73-82.

RUSSOWSKI D; NICOLOSO FT. 2003. Nitrogênio e fósforo no crescimento de plantas de ginseng brasileiro [Pfaffia glomerata (Spreng.) Pedersen] cultivadas in vitro. Ciência Rural 33: 57-63.

UNEMOTO LK; FARIA RT; MENEGUCE B; ASSIS AM. 2006. Estabelecimento de um protocolo para a propagação in vitro de rainhado-abismo, Sinningia leucotricha (Hoehne) Moore - (Gesneriaceae). Acta Scientiarum - Agronomy 28: 503-506.

VANCE CP; UHDE-STONE C; ALLAN DL. 2003. Phosphorus acquisition and use: critical adaptations by plants for securing a nonrenewable resource. New Phytologist 157: 423-447.

YIN X; LANTINGA EA; SHAPENDONK AHCM; ZHONG X. 2003. Some quantitative relationships between leaf area index and canopy nitrogen content and distribution. Annals of Botany 91: 893-903. 